\title{
Author Correction: Intergenerational equity can help to prevent climate change and extinction
}

Adrian Treves, Kyle A. Artelle, Chris T. Darimont, William S. Lynn, Paul Paquet, Francisco J. Santiago-Ávila, Rance Shaw and Mary C. Wood

Correction to: Nature Ecology \& Evolution https://doi.org/10.1038/s41559-018-0465-y, published online 18 January 2018.

The original Article mistakenly coded the constitutional rights of Australia as containing a governmental duty to protect the environment (blue in the figures); this has been corrected to containing no explicit mention of environmental protection (orange in the figures). The original Article also neglected to code the constitutional rights of the Cayman Islands (no data; yellow in the figures); this has been corrected to containing a governmental duty to protect the environment (blue in the figures).

Although no inferences changed as a result of these errors, many values changed slightly and have been corrected. The proportion of the world's nations having constitutional rights to a healthy environment changed from $75 \%$ to $74 \%$. The proportions of nations in different categories given in the Fig. 1 caption all changed except purple countries (3.1\%): green countries changed from $47.2 \%$ to $46.9 \%$; blue countries changed from $24.4 \%$ to $24.2 \%$; and orange countries changed from $25.3 \%$ to $25.8 \%$. The proportion of the global atmospheric $\mathrm{CO}_{2}$ emitted by the 144 nations changed from $72.6 \%$ to $74.4 \%$; the proportion of the world's population represented by the 144 nations changed from $84.9 \%$ to $85 \%$. The values of annual average $\mathrm{CO}_{2}$ emissions for blue countries changed from $363,000 \mathrm{Gg}$ to $353,000 \mathrm{Gg}$ and for orange countries from $195,000 \mathrm{Gg}$ to $201,000 \mathrm{Gg}$. The proportion of threatened mammals endemic to a single country represented by the 144 countries changed from $91 \%$ to $84 \%$. Figures $1-3$ have been updated to show the correct values and map colours and the Supplementary Information has been updated to give the correct country codes. 